\title{
ANÁLISE CRÍTICA DO DISCURSO DO \\ PROGRAMA NACIONAL DE FORMAÇÃO DE EDUCADORAS(ES) AMBIENTAIS - PROFEA: PELA NÃO DESESCOLARIZAÇÃO DA EDUCAÇ̃̃O AMBIENTAL
}

\author{
Leonardo Kaplan* \\ Carlos Frederico Bernardo Loureiro**
}

RESUMO: Sob os referenciais da Análise Crítica do Discurso e da Educação Ambiental Crítica, são analisados o Programa Nacional de Formação de Educadores Ambientais (ProFEA) e textos com conceituações-chave para as políticas públicas em Educação Ambiental (EA). Com a análise discursiva feita verifica-se que as relações entre a EA e a escola são apresentadas em duas direções coincidentes: busca-se afastar ou secundarizar tais práticas do contexto escolar, transferindo-as para outros espaços vistos como mais compatíveis à prática educativa ambiental; e, quando estas ações estão voltadas para a inserção nas escolas, nem sempre são concebidas e realizadas em diálogo com a comunidade e os conhecimentos escolares, entrando, portanto, de modo periférico no "mundo da educação", não tocando em questões centrais de sua materialidade. Assim, o ProFEA propõe uma ação formativa sem centralidade na escola e nos agentes da educação. Defende-se aqui a entrada da EA nas escolas públicas pela "porta da frente".

Palavras-chave: Educação Ambiental; Análise Crítica do Discurso; Políticas Públicas.

\section{CRITICAL DISCOURSE ANALYSIS OF THE \\ PROGRAMA NACIONAL DE FORMACְ̃̃O DE EDUCADORES AMBIENTAIS/PROFEA: AGAINST ENVIRONMENTAL EDUCATION (EE) WITHDRAW FROM SCHOOL}

ABSTRACT: Considering Critical Discourse Analysis and Critical Environmental Education as the theoretical basis of this work, we analyse the Programa Nacional de Formação de Educadores(as) Ambientais (National Program for the formation of environmental educators) and also some texts with key concepts for public politics in Environmental Education (EE). In this work, discourse analysis shows that the relation

\footnotetext{
* Mestre em Educação pela Universidade Federal do Rio de Janeiro (UFRJ); Professor de Biologia e Ciências das redes públicas estadual e municipal do Rio de Janeiro e Membro do Laboratório de Investigações em Educacãa, Ambiente e Sociedade da Universidade Federal do Rio de Janeiro (LIEAS/FE/UFRJ). E-mail: leonardokaplan@gmail.com

* *Doutor em Serviço Social pela Universidade Federal do Rio de Janeiro (UFRJ); Professor dos Programas de Pós-graduação em Educação e em Psicossociologia de Comunidades e Ecologia Social da Universidade Federal do Rio de Janeiro (UFRJ); Coordenador do Laboratório de Investigações em Educação, Ambiente e Sociedade da Universidade Federal do Rio de Janeiro (LIEAS/FE/UFRJ) e Pesquisador CNPq. E-mail: floureiro@openlink.com.br
} 
between $\mathrm{EE}$ and school is presented in two coincident directions: on the one hand, it is intended to take those practices out of the school context, transferring them for other spaces considered more compatible with EE practices; on the other hand, when those actions are aimed at school integration, they are not always conceived and done as a dialogue between community and school knowledge. Therefore, they are not included or referred to as central questions for the educational context. Thus, ProFEA suggests that formation actions are not centered at school and the educational agents. This work advocates the entry of EE in public schools by the "front door".

Keywords: Environmental Education; Critical Discourse Analysis; Public Politics.

\section{Introdução}

Desde a constituição do campo, ainda muito recente, a educação ambiental (EA) estabeleceu uma relação com a educação repleta de contradições e distanciamentos, com poucos e rasos diálogos. Isso resulta em dois problemas determinantes. Podem ser observadas dificuldades da comunidade escolar no entendimento da complexidade da EA expressa nas finalidades apresentadas em diferentes políticas públicas federais e em outros materiais historicamente produzidos e apropriados na e dentro da área (LOUREIRO, 2007, p. 1). Por sua vez, os educadores ambientais, não raramente, mostram desconhecer a dinâmica escolar, o que os leva a produzir afirmações de cunho normativo, prescritivo e idealizado relativos à inserção da EA nas escolas, sem a devida preocupação e o cuidado de serem analisados o cotidiano escolar e sua relação com as condições objetivas e materiais que situam tanto a escola quanto a EA numa sociedade estruturada em classes (LOUREIRO; LIMA, 2007 apud LOUREIRO, 2007, p. 1-2).

Refletir sobre a EA na escola é pensar sobre as relações entre educação, escola e sociedade. Explicitar tal pressuposto é relevante, mesmo que aparentemente óbvio, pois possibilita que se parta da compreensão de que o processo educativo é um processo de formação humana, de constituição dos indivíduos sociais em suas singularidades, no qual os seres humanos, inacabados em sua humanidade ao nascerem, se produzem como humanos (TOZONI-REIS, 2008, p. 46). Logo, para essa perspectiva assumida no artigo, é necessário compreender a educação em termos concretos, não descolada das relações sociais que definem sua institucionalização, vinculando-a ao processo global de produção da existên- 
cia humana, enquanto prática social determinada materialmente (SAVIANI, 2005, p. 15), sob pena de chegarmos a proposições afastadas da realidade sócio-histórica.

Com a modernidade, a instituição que tem assumido prioritariamente a função formativa é a escola. Contudo, não podemos perder de vista que esta se conforma na sociedade capitalista e que isso tem rebatimentos na sua dinâmica conflitiva de funcionamento, em que se produzem processos dialéticos de reprodução ideológica de verdades dos grupos e classes dominantes e movimentos de resistência e de recontextualização em seu interior (BERNSTEIN, 1996). É nessa dinâmica que a materialidade da escola se manifesta e sua legitimidade social se impõe.

Com o subtítulo do trabalho, manifesta-se a intenção clara de "convidar" os educadores, no caso particular os educadores ambientais, a se inserirem na defesa da EA nas escolas, enquanto espaço institucional significativo e universalizante de formação, práticas pedagógicas, de disputa entre visões de mundo e construção de hegemonia. $\mathrm{O}$ adjetivo "desescolarizada" não foi escolhido por acaso no "chamar a atenção" para tal finalidade. A inspiração veio do livro de Ivan Illich, intitulado em português Sociedade sem escolas, tendo como título original Deschooling society, que poderia ser melhor traduzido como "Desescolarizando a sociedade". Este foi um clássico na educação dos anos 1970 no Brasil e corresponde a determinada posição diante das escolas de negação de sua relevância em instituir processos universalistas e igualitários, mesmo que de modo contraditório em uma sociedade desigual produtora de mercadorias, que é recorrente na EA.

A negação da negação também não foi casual na problematização dessa posição na educação ambiental. Segundo Fairclough (2001a, p. 156-157), as frases negativas frequentemente são usadas com finalidades polêmicas, carregando tipos especiais de pressuposição que também funcionam intertextualmente, incorporando outros textos para contestá-los ou rejeitá-los. Com isso, o título expressa de forma direta o objetivo do artigo, que é analisar o Programa Nacional de Formação de Educadoras(es) Ambientais - por um Brasil educado e educando ambientalmente para a sustentabilidade (ProFEA), à luz da análise crítica do discurso, produzida por Norman Fairclough, e da abordagem crítica da EA, evidenciando suas tendências discursivas e criticando-as com vistas à defesa da consolidação da EA no contexto escolar. Nesse sentido, a argumentação elaborada remete à 
necessidade de sua entrada nas escolas pela "porta da frente", com a garantia de políticas públicas democraticamente instituídas em diálogo com diversos agentes sociais, em particular os trabalhadores da educação e suas formas de organização coletiva.

A análise discursiva do referido documento, portanto, é feita a partir de seu contexto de produção, o que passa por considerar ações governamentais que o antecipam ou que o seguem, bem como incorporar outros textos às análises, como a Política Nacional de Educação Ambiental (PNEA) e outros, trabalhando com a intertextualidade do material analisado.

\section{Políticas públicas em educação ambiental e o contexto escolar: a escolha do objeto de pesquisa}

É notório um movimento, no país, nas últimas décadas, de construção de políticas públicas em educação ambiental, nos níveis nacional, estadual e municipal (LOUREIRO, 2008, p. 2). Em especial, a partir dos anos 1990, esse movimento tem chegado às escolas por meio da criação e implementação de diretrizes e políticas públicas para promover e incentivar a EA no ensino fundamental (LOUREIRO; COSSIO, 2007, p. 1). Um primeiro olhar, a partir das informações obtidas na pesquisa "O que fazem as escolas que dizem que fazem educação ambiental?”, elaborada pelo Ministério da Educação (MEC) e iniciada em 2005, nos permite apontar para um importante processo de universalização do acesso à EA nas escolas brasileiras, embora ainda falte avaliar suas reais condições de inserção, as modalidades e as práticas. A partir dos Censos Escolares entre 2001 e 2004, verificou-se que, em 2001, o percentual de escolas que a ofereciam era de 61,2\% e, em 2004, esse patamar chegou aos 94\%. A inserção da EA tem sido feita basicamente por três caminhos: projetos, disciplinas especiais e inserção da temática ambiental nas disciplinas (TRAJBER; MENDONÇA, 2006, p. 12).

$\mathrm{O}$ documento referente às políticas públicas em EA analisado neste trabalho é o Programa Nacional de Formação de Educadoras(es) Ambientais - por um Brasil educado e educando ambientalmente para a sustentabilidade (ProFEA). Essa escolha pode ser justificada por este ser um documento que materializa uma política pública voltada para a formação em educa- 
ção ambiental e que tem servido de referência básica para inúmeras ações federais e estaduais nessa direção e particularmente para o universo escolar, via sua apropriação pelo MEC e pelo Órgão Gestor da Política Nacional de Educação Ambiental. Além disso, de modo complementar, foram selecionados textos que servem de base para alguns conceitos, concepções e pressupostos que aparecem de modo não suficientemente desenvolvido no ProFEA, mas que são constitutivos desse, garantindo que seus fundamentos possam ser melhor compreendidos e problematizados.

Ainda que identifiquemos que a EA tem entrado na agenda das políticas públicas, tanto via Ministério do Meio Ambiente quanto via Ministério da Educação, por intermédio do Órgão Gestor da Política Nacional de Educação Ambiental, é preciso investigar em que medida as políticas públicas em EA estão respondendo a pressões sociais, quais os sentidos dessas pressões e, no caso das escolas, quais influências essas políticas têm sobre o cotidiano escolar. Em outras palavras, em vez de tão somente comemorarmos a existência de políticas públicas em EA para o contexto escolar, deveríamos analisar quais os seus objetivos, justificativas, implicações e consequências políticas, sociais e educacionais para os atores sociais envolvidos (professores, estudantes, servidores, direção, pais e comunidade do entorno da escola).

\section{Análise Crítica do Discurso: a opção metodológica}

A Análise Crítica do Discurso constitui-se como uma área de estudos iniciada no final dos anos de 1970, a partir da combinação das contribuições da linguística crítica - sendo Halliday a maior influência -, do marxismo gramsciano e da Escola de Frankfurt. Essa característica formativa confere uma possibilidade de vincular a análise detalhada de textos linguísticos com uma orientação social para o discurso. Conforme Fairclough (2001a, p. 31-32), é possível dividir as abordagens de Análise do Discurso em dois grupos, segundo a natureza de sua orientação social para o discurso: "não-críticas" e "críticas", não sendo esta uma divisão absoluta. 
As abordagens críticas diferem das abordagens não-críticas não apenas na descrição das práticas discursivas, mas também ao mostrarem como o discurso é moldado por relações de poder e ideologias e os efeitos construtivos que o discurso exerce sobre as identidades sociais, as relações sociais e os sistemas de conhecimento e crença, nenhum dos quais é normalmente aparente para os participantes do discurso.

Fairclough (1999, p. 71), especificamente, discute a relação entre discurso, conhecimento e mudança social. Ele afirma que as mudanças contemporâneas vêm afetando o papel da linguagem na vida social e, por isso, aponta para a necessidade de se desenvolver uma consciência crítica da linguagem ${ }^{1}$ como pré-requisito para uma cidadania democrática efetiva. A importância dessa consciência crítica do discurso passa por compreender como os discursos podem atuar ideologicamente nas relações sociais e de poder.

Esse autor trabalha o termo "discurso" considerando "o uso de linguagem como forma de prática social e não como atividade puramente individual ou reflexo de variáveis situacionais" (FAIRCLOUGH, 2001a, p. 90), entendendo este como "um modo de ação, uma forma em que as pessoas podem agir sobre o mundo e especialmente sobre os outros, como também um modo de representação" (p. 91). Assim, se diferencia de abordagens que entendem o discurso como fonte de determinação da realidade (perspectivas performativas) e de outras que compreendem o discurso como sendo um mero reflexo determinado pela realidade, de forma unilateral e determinista. Para os primeiros, mudanças de ordem discursiva (ex.: inclusão de novas palavras, modalidades e gêneros discursivos, ressignificação e relexicalização, etc.) resultam diretamente em mudanças sociais. Já para os últimos, o discurso muda quase que automaticamente devido às mudanças sociais. Para Fairclough, trata-se de considerarmos uma relação dialética entre o discurso e a estrutura social e entre esta e as práticas sociais.

Por essa perspectiva dialética, por um lado, "o discurso é moldado e restringido pela estrutura social no sentido mais amplo e em todos os níveis: pela classe e por outras relações sociais em um nível societário" e, por outro, "o discurso é socialmente constitutivo", contribuindo "para a constituição de todas as dimensões da estrutura social que, direta ou indiretamente, o moldam e o restringem" (FAIRCLOUGH, 2001a, p. 91). Portanto, as pessoas não são simplesmente colonizadas pelos discursos, 
mesmo considerando que eles apresentam efeitos ideológicos, pois elas também se apropriam deles e os trabalham de maneiras particulares. Esse processo de colonização-apropriação é também dialético, já que depende da posição social dos indivíduos e grupos sociais, o que significa que as pessoas não estão incondicionalmente livres para "pegar" os textos (FAIRCLOUGH, 1999, p. 75-76). Sintetizando, “a constituição discursiva da sociedade não emana de um livre jogo de idéias nas cabeças das pessoas, mas de uma prática social que está firmemente enraizada em estruturas sociais materiais, concretas, orientando-se para elas" (FAIRCLOUGH, 2001a, p. 93).

Fairclough formulou uma teoria tridimensional de discurso, buscando distinguir e relacionar: o texto, a prática discursiva e a prática social. O conceito de texto é o sentido amplo utilizado por Halliday, ou seja, linguagem falada e escrita, depois passando a incluir outros materiais semióticos. O texto é o produto, enquanto o discurso, o processo. A prática discursiva é uma forma particular de prática social. Em alguns casos, a prática social pode ser inteiramente discursiva, enquanto em outros pode haver uma mescla com práticas não-discursivas. As análises das práticas discursivas envolvem os processos de produção, distribuição e consumo textual, sendo que todos esses processos são sociais e exigem referência aos ambientes econômicos, políticos e institucionais nos quais os discursos são gerados. Esse autor tem afirmado que a sociedade contemporânea é cada vez mais textualmente-mediada, o que significa que conhecimentos técnicos e discursos chegam a nós via textos de vários tipos (livros, revistas, programas de televisão e rádio, etc.) que medeiam nossas vidas sociais (FAIRCLOUGH, 1999, p. 75).

Dois conceitos são centrais na caracterização do discurso como prática social: ideologia e hegemonia. Fairclough, quanto ao primeiro conceito, parte de Althusser e Thompson e considera que "as ideologias são significações/construções da realidade (o mundo físico, as relações sociais, as identidades sociais) que são construídas em várias dimensões das formas/sentidos das práticas discursivas e que contribuem para a produção, a reprodução ou a transformação das relações de dominação" (FAIRCLOUGH, 2001a, p. 117). Além disso, é importante afirmar que as práticas discursivas e a própria linguagem se apresentam como formas materiais da ideologia. No entanto, não é possível "ler" as ideologias nos textos, porque os sentidos são produzidos por meio de interpretações dos 
textos e os textos estão abertos a diversas interpretações (FAIRCLOUGH, 2001a, p. 118-119). Apesar dessa abertura, cabe afirmar que os sentidos são múltiplos, mas não quaisquer, pois são localizados histórica e socialmente.

Os sentidos das palavras são ideológicos. Mas não apenas estes. Outros aspectos semânticos como as pressuposições, as metáforas e a coerência também são investidos ideologicamente. Segundo Bahktin (2004), não há linguagem sem ideologia. Nem sempre as pessoas têm consciência das dimensões ideológicas de suas próprias práticas discursivas, mesmo quando assumem posição de resistência, contribuindo para o enfrentamento da ideologia dominante. Fairclough (p. 121) defende que apesar dos sujeitos serem posicionados ideologicamente, também são capazes de agir criativamente no sentido de realizar suas próprias conexões entre as diversas práticas e ideologias a que são expostos e de reestruturar as práticas e as estruturas posicionadoras.

O conceito de hegemonia, Fairclough (p. 122) toma a partir de Gramsci:

Hegemonia é o poder sobre a sociedade como um todo de uma das classes economicamente definidas como fundamentais em aliança com outras forças sociais, mas nunca atingido senão parcial e temporariamente, como um 'equilíbrio instável'. Hegemonia é a construção de alianças e a integração muito mais do que simplesmente a dominação de classes subalternas, mediante concessões ou meios ideológicos para ganhar seu consentimento.

Trazendo para as práticas discursivas esse conceito de hegemonia, Fairclough (p. 123-124) coloca que a prática discursiva, em seus diferentes níveis (produção, distribuição e consumo textual, além da interpretação), é uma faceta da luta hegemônica que contribui em diferentes graus para a reprodução e para a transformação não somente da ordem de discurso existente, mas também das relações sociais e assimétricas existentes. Em suma, podemos identificar a hegemonia como uma estratégia de universalização do particular (FAIRCLOUGH, 2003, p. 46). Assim, buscar hegemonia é uma questão de buscar universalizar sentidos particulares a serviço de alcançar e manter a dominação e seu trabalho ideológico (p. $58)$. 


\section{Análise crítica do discurso do ProFEA com base nas escolas}

A primeira consideração é a de que muitos argumentos, justificativas, pressupostos e embasamentos teóricos que aparecem no ProFEA são comuns também à Política Nacional de Educação Ambiental (PNEA), lei federal n. 9.795/99, que regulamenta a EA no Brasil, e ao Programa Nacional de Educação Ambiental (ProNEA). Como pressupostos, entende-se as proposições que são tomadas pelos produtores do texto como já estabelecidas ou "dadas" e há várias pistas formais na organização da superfície do texto para mostrar isso (FAIRCLOUGH, 2001a, p. 155). É principalmente nesses discursos comuns que se concentra a análise, sobretudo por serem os mais significativos em relação à concepção hegemônica de educação ambiental (incidindo mais diretamente sobre a educação escolar).

Alguns conceitos e ideias-chave situadas nas políticas foram buscados em outros textos, fazendo um exercício no sentido de apontar a intertextualidade destas. A intertexualidade é uma propriedade dos textos que indica que eles são constituídos por elementos de outros textos, em um movimento no qual o texto responde, reacentua e retrabalha textos passados, ajudando a fazer história e contribuindo para processos de mudança mais amplos, antecipando e tentando moldar textos subsequentes.

Após ter sido debatido e elaborado em 2003, a partir da Linha de Formação e consolidado no ano seguinte, o ProFEA foi lançado em 2006. Objetiva

\footnotetext{
qualificar as políticas públicas federais de educação ambiental para que exijam menos intervenções diretas e ofereçam mais apoio supletivo às reflexões e ações autogeridas regionalmente, no sentido de desenvolver uma dinâmica nacional contínua e sustentável de processos de formação de educadoras(es) ambientais a partir de diferentes contextos (BRASIL, 2006, p. 5).
}

Logo no início, o ProFEA, formulado pelo Órgão Gestor da PNEA, embora seu prefácio seja assinado apenas pela Diretoria de Educação Ambiental do Ministério do Meio Ambiente (DEA/MMA), é apresentado como "um documento técnico" e "uma peça de comunicação, um convite ao diálogo" (BRASIL, 2006, p. 3, grifos nossos). O Órgão Gestor afirma que não pode realizar seus intentos sem a participação ativa de diversos parceiros (BRASIL, 2006, p. 3, grifos nossos). Que diálogo é esse? 
Quem são os envolvidos? Quais as relações sociais e de poder que estão em jogo entre eles? Considerando que esse é um termo polissêmico, apropriado por diferentes agentes sociais, mas dominantemente presente em uma lógica de Estado Gerencial, de que tipo de parcerias está se falando? Será que dá pra falar em documento técnico, ocultando sua conotação política? Essas formulações apontam para uma retirada de desigualdades e assimetrias dos direitos, das obrigações e do prestígio discursivo e linguístico dos gupos de pessoas. É a hegemonia assumindo novas formas (FAIRCLOUGH, 2001a, p. 248-249). Trata-se de uma eliminação aparente de marcadores de assimetria explícitas de poder, de uma substituição de mecanismos explícitos de controle por mecanismos encobertos (FAIRCLOUGH, 2001a, p. 251).

Chega a ser afirmado no documento que as atuações dos educadores ambientais reunidos em redes estariam "produzindo sinergia, orientando as políticas públicas de educação ambiental” (BRASIL, 2006, p. 3, grifo nosso), como se todas apontassem para a mesma direção e como se todos os educadores estivessem ou devessem estar organizados em redes (sendo isso um pressuposto que desconsidera movimentos sociais, sindicatos e outras formas organizacionais). Logo em seguida, seus autores reconhecem que "esta materialidade [das propostas reunidas no ProFEA] não é homogênea" e que deve-se fazer "emergir ainda mais a sociodiversidade brasileira" (BRASIL, 2006, p. 4). Cabe questionar se as orientações do documento permitem que as tensões entre os educadores ambientais apareçam, já que não se trata de tentar homogeneizar as propostas, de acordo com o que dizem seus autores. Do jeito como está, fica a impressão de que as propostas apresentadas e as formas de organização indicadas (as redes) contemplam, igual ou parcialmente, todas as concepções políticas de todos os educadores ambientais. Assim, mais do que uma pretensão, essa é uma forma de buscar silenciar as disputas internas em torno do rumo das políticas públicas em educação ambiental. Dessa forma, os formuladores do ProFEA vão construindo sua hegemonia no campo em disputa da EA.

Como procedimentos metodológicos do programa de formação são indicados processos educacionais, eixos metodológicos e modalidades de ensino. Onde aparece a EA escolar ("Educação por meio da escola e outros espaços ou estruturas educadoras") é o foco de análise. Nem no título a escola tem centralidade, dividindo terreno com outros espaços. De 
início, os formuladores do documento reconhecem que "a principal estrutura educadora construída na nossa sociedade e que é resultado de amplas lutas pela democratização do acesso à educação é, sem dúvida, a Escola" (assim com letra maiúscula mesmo). Mas, prosseguindo, aparecem os poréns: "entretanto, na perspectiva desta proposta a educação faz parte da vida e como tal deve estar planejada para diferentes espaços e estruturas" (BRASIL, 2006, p. 22, grifos nossos). Está implícita aí a concepção de que a educação escolar é insuficiente, pois não "faz parte da vida", não é uma educação permanente ou aprendizagem ao longo da vida.

Segundo Fairclough (2000, p. 48-49), um recente estudo sobre a expressão educação permanente (lifelong learning) indica que está em curso uma reestruturação radical na relação entre os domínios (e linguagens) da economia e da educação. Uma mostra disso é o trecho a seguir, extraído de um livro que defende essa proposta e assume suas origens, vinculando a educação às "inevitáveis" mudanças tecnológicas e no mundo do trabalho:

\footnotetext{
A aprendizagem ao longo da vida é um negócio incerto. (...) a direção rumo à sociedade da aprendizagem tem sido acelerada (...) pelo menos tanto pela força das mudanças sociais e culturais como pelo desenvolvimento econômico e tecnológico. Uma consequência dessas mudanças tem sido que a aprendizagem permanente tem sido ela mesma uma dimensão chave no processo de exclusão social e desigualdade - não apenas na esfera do emprego e da renda, mas também em outros campos como cosumo, bem-estar pessoal, saúde e cidadania (FIELD, 2006, p. 145).
}

Conforme aponta Gadotti ${ }^{2}$ (2008, p. 100), a Educação Permanente, quando posta no plano genérico ou como solução para os problemas educacionais, ignorando as contradições vivas nas instituições escolares, tende a tornar-se um projeto reprodutor das relações sociais capitalistas à medida que não coloca em questão a função da educação numa sociedade de classes. Acaba por se fazer um apelo pelo "aprender na vida", desconsiderando as determinações históricas em que o processo de formação humana se insere. É um movimento de educação fora da escola e do sistema educacional formal que não é novo (se inicia em $1919^{3}$ ) e ganha maior dimensão no final dos anos 1960. Não por acaso, tal discurso foi desenvolvido e encampado por organismos internacionais tais quais a Unesco, o Conselho da Europa, a OCDE e o Banco Mundial, 
o que ilustra qual é o seu caráter político-ideológico e econômico dominante. A educação é parte do processo de mudança, mas jamais deve ser tomada à parte do contexto social geral. Logo, o objetivo da Educação Permanente, quando não está posto como processo social contraditório e possível de ser apropriado pelas lutas sociais nos diferentes espaços de formação, acaba sendo materializado por aqueles que têm condições sociais e econômicas melhores para estudar. Além disso, responsabiliza-se (e culpabiliza-se) cada indivíduo pela sua formação. Isso permite que se esqueceça da desigualdade inicial na concorrência para a formação (GADOTTI, 2008, p. 97).

Passando agora aos objetivos do ProFEA (BRASIL, 2006, p. 7), o primeiro confirma o interesse por organizar a formação de educadores ambientais "a partir de diferentes contextos", o que não seria problemático se fosse deixado claro que há e quais são as prioridades entre eles. O segundo fala em "apoiar e estimular processos educativos que apontem para transformações éticas e políticas em direção à construção da sustentabilidade socioambiental" (grifos nossos). É interessante notar que não são mencionadas transformações sociais. Isso individualiza e moraliza as discussões.

Posteriormente, é objetivo "fortalecer as instituições e seus sujeitos sociais para atuarem de forma autônoma, crítica e inovadora em processos formativos, ampliando o envolvimento da sociedade em ações socioambientais de caráter pedagógico" (grifos nosso). Aqui está sendo criticada alguma forma considerada ultrapassada de atuação das instituições e dos sujeitos. Além disso, é sugerido ampliar a participação da sociedade. Tendo em vista que sociedade civil é um conceito em disputa ${ }^{4}$, é necessário dizer que agentes e grupos sociais se quer fortalecer e envolver nos processos formativos em educação ambiental. Silenciar e omitir essas informações é também um posicionamento político, pois na ausência de um controle social definido por parte do Estado, quem prevalece, em uma desigual sociedade de classes, são os grupos sociais econômica e politicamente dominantes.

Por último, é objetivado "contribuir na estruturação de um Observatório em rede das Políticas Públicas de formação de Educadoras(es) Ambientais, através da articulação permanente dos Coletivos Educadores". Neste Observatório, melhor explicado posteriormente, "diversos Coletivos articulam conhecimentos, experiências, metodologias para se avaliarem, para sistematizarem informações, para formula- 
rem propostas políticas, para incrementarem o rol de possibilidades de troca entre os coletivos. Esta articulação que entendemos como Observatório em Rede se torna a interlocutora das políticas públicas nos diferentes níveis do Estado e da Sociedade Civil' (p. 14-15, grifos nossos). A avaliação cabe, portanto, à sociedade civil, na figura dos Coletivos Educadores, e não ao Estado, na figura do Órgão Gestor da PNEA. Isso é delicado à medida que não se tem certeza e garantia alguma quanto aos interesses que estão em jogo nessas autoavaliações, pois, como dissemos anteriormente, não há sequer explicitação de qual a natureza da sociedade civil que compõe essas organizações.

Na concepção político-pedagógica do ProFEA, são apresentados alguns princípios e estatégias, praticamente todos insuficientemente conceituados ou problematizados no resto do documento, entre os quais estão "Coletivos Educadores", "Inter e transdisciplinaridade", "Comunidades de Aprendizagem" e "Cardápio de Aprendizagem". Essas propostas são abordadas na próxima seção, indicando diálogos com a desescolarização da sociedade e relacionando-as a um movimento de deslegitimação da EA na e da escola.

\section{Não desescolarizando a educação ambiental na sociedade}

Conforme apontado no início, esse título faz menção ao livro Sociedade sem escolas, publicado em 1971, e que teve grande repercussão no meio educacional. Apesar de datado, alguns aspectos podem ser levantados ainda atualmente, dada sua ocorrência na educação ambiental. Para mostrar os paralelos, foram selecionados alguns trechos de textos do livro Encontros e Caminhos: formação de educadoras(es) ambientais e coletivos educadores, produzido pela DEA/MMA (FERRARO JR., 2005; 2007) e que contém conceitos e propostas-chave utilizados na área. Foi intencional trazer o livro de Ivan Illich para sustentar a crítica às políticas de Educação Ambiental analisadas. Embora tal autor não seja citado na coletânea em questão, nem no ProFEA, sua linha de argumentação é similar à abordada no ProFEA para justificar a "desescolarização" da educação ambiental, propiciando um diálogo crítico oportuno.

Ivan Illich defende que a sociedade deve e pode ser desescolarizada. Para ele não é possível uma educação universal por meio da escola, 
sendo mais factível se fosse tentada por outras instituições. Propõe como saída uma "teia educacional", aumentando a oportunidade de cada um de transformar todo instante de sua vida num instante de aprendizado, de participação, de cuidado (ILLICH, 1973, p. 18). No texto sobre Contextos de aprendizagem, falando dos encontros e eventos mundiais, é dito que a EA "se inscreve na sociedade em movimentos tangenciais de aprendizagem, para além da escola, ganhando outros espaços culturais, de comunicação, e de informação" (TRISTÃO; FASSARELLA, 2005, p. 92, grifo nosso). Como colocam Barreto et al. (2006, p. 40), nesse tipo de discurso há um deslocamento "de não se aprende somente na escola para não se aprende na escola". As autoras de Contextos de aprendizagem falam de "uma educação plural, podendo até ser entendida como formalizada na escola, mas no 'Encontro', ela é desejosa na esquina, compenetrada no bairro, articulada com a cidade, enamorada de suas áreas verdes" (TRISTÃO; FASSARELLA, p. 90, grifos nossos). "Para além da escola" retira sua centralidade no processo educativo, transferindo esse papel para outras instituições. O emprego da conjunção adversativa "mas" traz implícita a ideia de que se, no "Encontro", a educação é desejosa, na escola isso não ocorre sem que se explicite o que se entende por "desejosa", "enamorada", etc. e o porquê de a escola, na sociedade capitalista atual, não permitir isso.

Illich (1973, p. 31) defende firmemente a autoaprendizagem, atribuindo à escola um "efeito anti-educacional sobre a sociedade". O autor afirma ainda que a maioria das pessoas adquire a maior parte dos seus conhecimentos fora da escola e que, portanto, é uma ilusão pensar que a maioria do que se aprende é resultado do ensino na escola (ILLICH, 1973, p. 37). Além disso, para ele, a maior parte da aprendizagem ocorre casualmente (p. 38). Defende ainda que as pessoas, em qualquer época de suas vidas, possam escolher um tipo de instrução, financiada com recursos públicos (p. 40). A proposta fica mais explícita quando ele fala em abrir o mercado para que as oportunidades de aprendizagem-treino possam ser vastamente multiplicadas, conjugando "o professor certo com o aluno certo quando bem motivado por um programa inteligente, sem o constrangimento de um currículo" (p. 42).

A proposta de "Cardápio de Aprendizagem" em EA questiona "os programas de formação estruturados em 'grades' e 'disciplinas', [pois] têm a característica de engessar o processo de formação, considerando os educandos como uma mesma massa uniforme, com os mesmos desejos e 
mesmas lacunas", sendo um "prato único, sem possibilidades de escolha" (TONSO, 2005, p. 52, grifo nosso). A relação entre os mundos da gastronomia e da educação é explicitada (correspondência entre "ementa" e "cardápio", em Portugal, e entre "saber" e "sabor"), mas a metáfora empregada não convence, uma vez que ignora que os conteúdos e arranjos curriculares na escola não são estáticos e expressam disputas concretas entre concepções de formação e no interior de cada disciplina, com movimentos repletos de recontextualizações, hibridizações e contradições (BERNSTEIN, 1996). Além disso, a ideia de um cardápio, na própria alimentação, pressupõe que as escolhas feitas sejam livres e iguais. Evidentemente, sabemos que isso não corresponde à realidade.

De acordo com Fairclough (2001a, p. 241), "as metáforas estruturam o modo como pensamos e o modo como agimos, e nossos sistemas de conhecimento e crença, de uma forma penetrante e fundamental". Não é possível estabelecer um vínculo coerente nos níveis simbólico ou material entre alimentos e conhecimentos para além da etimologia e dos sinônimos desses termos em alguns locais. O emprego dessa metáfora tem um sentido ideológico (FAIRCLOUGH, 2001a, p. 289) de deslegitimar epistemologicamente os currículos. No entanto, isso é feito de modo incoerente ao se tentar uma "transferência metafórica" (p. 256) de um vocábulo do contexto gastronômico para a ordem de discurso educacional.

Cada "elenco de atividades (...) que tem por objetivo proporcionar a formação (...) de Educadores Ambientais" (p. 49) deve ser definido pelos integrantes dos Coletivos Educadores (p. 51). É dito que partindo dos conceitos, metodologias e estratégias pedagógicas apresentadas, o "ProFEA constitui-se na base para as construcões participativas de Projetos Políticos Pedagógicos, contextualizadas territorialmente pelos Coletivos Educadores" (p. 6). Ou seja, os professores não podem definir os conteúdos, as metodologias e as atividades, mas esses Coletivos podem. Aqui vemos explicitado o conceito de "parceria" adotado anteriormente no documento. Uma parceria entre quem vive, trabalha e conhece o cotidiano da escola e quem é alheio a essa realidade. Os Coletivos Educadores seriam a "união de pessoas que trazem o apoio de suas instituições para um processo de atuação educacional em um território" e "favorecem a continuidade e permanência de processos educacionais, a consistência e adequação das propostas de formação, a otimização de recursos locais, regionais e 
federais", entre outras ações (FERRARO JÚNIOR; SORRENTINO, 2005, p. 59, grifos nossos). Os autores do ProFEA consideram a "formação de Coletivos Educadores uma das suas estratégias essenciais de implementação" (BRASIL, 2006, p. 5). Note-se que a pretensão de eliminação das disputas e das assimetrias de poder é uma tendência desse discurso de democratização, dando a impressão de que todos convergem ou deveriam convergir na mesma direção, de modo positivo e com uma visão bastante idealizada da sociedade estruturada em classes. Não é apresentada a contradição entre o caráter público e o privado, seja das instituições, dos interesses e das lógicas dos grupos que compõem os Coletivos Educadores, seja de suas instâncias e espaços de atuação. Quem compõe um Coletivo Educador, afinal? Nas palavras de seus formuladores (FERRARO JÚNIOR; SORRENTINO, 2005, p. 61):

O Coletivo pode ser constituído por educadores de diferentes instituições que desenvolvam ações formativas no campo da educação ambiental, da educação popular, da formação de professores, da extensão rural, da formação técnica socioambientalista, dentre os mais diferentes setores, nas Universidades, nas Secretarias de Educação, nas Secretarias de Meio Ambiente, nos NEAS do IBAMA, nas ONGs, nas Pastorais, nas Federações Sindicais, nas CIEAS, nas Redes de Educação Ambiental, nos Movimentos Sociais.

Todas são apresentadas como possibilidades igualmente válidas. É como se a contradição público/privado fosse secundária e, portanto, pudesse ser superada e conciliada em prol de "um mundo melhor". Essa proposta torna-se mais contraditória ainda quando se firma como política pública, inclusive com financiamento do Estado, ou seja, recursos públicos, para as ações desses Coletivos, que podem atender a interesses e entrar numa lógica privada. O eixo da discussão então deixa de ser a contradição entre o público e o privado e se desloca para questões éticas, das boas intenções, e de ter capacidade, habilidade e "competência" para executar tais ações. Esses discursos há algum tempo já foram apropriados pelo empresariado e pelas $\mathrm{ONGs}^{5}$. Isso esvazia a discussão política sobre a natureza das políticas públicas, o caráter classista e o papel do Estado. Além disso, "otimização" é um exemplo de comodificação do discurso, isto é, o processo de colonização de discursos pelo discurso relacionado à produção de mercadorias, commodities (FAIRCLOUGH, 2001a, p. 255). Nada mais próprio da lógica privada. 
Illich (1973, p. 47) propõe como alternativa à escola uma rede ou um sistema de serviços que dê a cada homem a mesma oportunidade de partilhar seus interesses com outros motivados pelos mesmos interesses, por meio de encontros educacionais, reuniões entre interessados em discutir um tema definido por eles mesmos. Ele próprio chama essa proposta de "instrução livre e competitiva" (p. 42), de "educação liberal" (p. 44). Esses encontros aproximam-se das "Comunidades Aprendentes", "cada uma destas unidades de vida e de destino", "pares, grupos, equipes, instituições sociais de associação e partilha da vida. Lugares onde lado a lado do que se faz como objetivo principal do grupo (...) as pessoas estão também inter-trocando saberes entre elas. Estão se ensinando e aprendendo" (BRANDÃO, 2005, p. 87). Com uma definição tão vaga como essa, fica até difícil de saber onde terminam as semelhanças e as diferenças entre esse conceito e o de Coletivos Educadores e o da proposta de rede que propõe Illich. O que fica evidente é o esvaziamento da escola já que

a escola é o lugar social da educação. Esta é uma idéia correta, mas não inteiramente. A educação que vivemos na escola (...) é uma fração importante de nosso aprendizado, mas não a única. A educação escolar é um momento de um processo múltiplo, de vários rostos e vivido entre diferentes momentos (p. 85).

Essa retirada do peso que a educação escolar tem está relacionada à defesa da educação permanente nos moldes idealizados e sem determinações sociais, cujos argumentos e críticas foram apresentados anteriormente. Ao mesmo tempo, esse movimento vem acompanhado da defesa do deslocamento para uma educação não-escolar a ser praticada por Coletivos Educadores. O problema não está na educação não-escolar, mas em como esta tem sido promovida. Com isso, a esfera pública das políticas sofre intervenções da esfera privada sem sequer haver esse debate e questionamento por parte dos educadores ambientais.

\section{Concluindo por agora}

Com este trabalho, foi possível identificar como a retirada da centralidade da escola tem sido materializada discursivamente no ProFEA, apoiado em alguns conceitos e propostas-chave que circulam na 
área. Sem ter a pretensão de esgotar essas discussões, este é apenas o começo para que voltemos a atenção para o que e como tem se feito educação ambiental nas escolas e no que consistem as políticas públicas em EA em curso.

É preciso ampliar e qualificar o debate, pois diversas e conflituosas concepções de educação ambiental, de escola, de políticas públicas, da relação público-privado, de Estado e de sociedade civil estão em jogo, disputando espaço e construindo hegemonia (mesmo por aqueles que negam o conceito por meio de um discurso de pluralidade e coexistência, como se não houvesse relações de poder e disputa material na conformação das políticas públicas). Ao se reconhecer que a escola não é o único espaço educativo, sua centralidade continua politicamente e epistemologicamente defensável e necessária por ser a instituição que, mesmo com todos os seus limites e contradições, democratiza e universaliza o acesso à educação como instrumento de luta para a emancipação social.

Assim, pode-se concluir com uma declaração de Paulo Freire (1991), o educador mais citado nos trabalhos acadêmicos em EA, que defendeu a

(...) escola como um espaço de educação popular voltado para a formação social crítica e para a sociedade democrática. A escola aberta para que o povo participe coletivamente da construção de um novo saber que leve em conta suas necessidades e se torne instrumento de luta, possibilitando-lhe transformar-se em sujeito de sua própria escola. Nesta perspectiva, a escola é também centro irradiador de cultura popular em permanente recriação e também espaço de organização política das classes populares. $O$ trabalhador deve encontrar nesta escola um lugar de debates de idéias, soluções, reflexões onde sistematizando sua própria experiência encontrará meios de auto-emancipação intelectual independentemente dos valores da classe dominante. 


\section{Referências}

BAKHTIN, M. Marxismo e filosofia da linguagem. 11 ed. São Paulo: Hucitec, 2004.

BARRETO, R. G.; GUIMARÃES, G. C.; MAGALHÃES, L. K. C.; LEHER, E. M. T. As tecnologias da informação e da comunicação na formação de professores. Revista Brasileira de Educação, v. 11, n. 31, p. 31-42, 2006.

BERNSTEIN, B. A estruturação do discurso pedagógico. Petrópolis: Vozes, 1996.

BRANDÃO, C. R. Comunidades aprendentes. In: FERRARO JÚNIOR, L. A. (Org.) Encontros e Caminhos: formação de educadoras(es) ambientais e coletivos educadores. v. 1. Brasília: MMA: Diretoria de Educação Ambiental, 2005. p. 85-91.

BRASIL. Órgão Gestor da Política Nacional de Educação Ambiental. Programa Nacional de Formação de Educadoras(es) Ambientais: por um Brasil educado e educando ambientalmente para a sustentabilidade, ProFEA. Brasília: Série Documentos Técnicos, n. 8, 2006. FAIRCLOUGH, N. Global Capitalism and Critical Awareness of Language. Language Awareness, v. 8, n. 2, p. 71-83, 1999.

FAIRCLOUGH, N. New labour, new language? London and New York: Routledge, 2000. FAIRCLOUGH, N. Discurso e mudança social. Brasilia: Editora Universidade de Brasília, 2001a. FAIRCLOUGH, N. The dialectics of discourse. Textus, v. 14, n. 2, p. 231-242, 2001b.

FAIRCLOUGH, N. In Intertextuality and assumptions. In: Analysing Discourse: Textual Analysis for Social Research. Londres e Nova York: Routledge, 2003. p. 39-61.

FERRARO JUNIOR, L. A. (Org.). Encontros e caminhos: formação de educadoras (es) ambientais e coletivos educadores Brasília: MMA, 2007. v. 2.

FERRARO JUNIOR, L. A. (org.). Encontros e caminhos: formação de educadoras (es) ambientais e coletivos educadores . Brasília: MMA, 2005. v. 1.

FERRARO JÚNIOR, L. A.; SORRENTINO, M. Coletivos Educadores. In: FERRARO JÚNIOR, L. A. (Org.) Encontros e Caminhos: formação de educadoras(es) ambientais e coletivos educadores. Brasília: MMA: Diretoria de Educação Ambiental, 2005. v. 1. p. 59-69.

FIELD, J. Lifelong learning and the new educational order. London: Trentham Books Limited, 2006. FREIRE, P. A paixão de mudar, de refazer, de criar. In: Universidade e sociedade. ANDESSN. Brasília. Ano I, n. 1, p. 47-50, fev/1991.

GADOTTI, M. Educação e poder: introdução à pedagogia do conflito. 15 ed. São Paulo: Cortez Editora, 2008.

ILLICH, I. Sociedade sem escolas. Petrópolis: Vozes, 1973.

LOUREIRO, C. F. B. Situando a educação ambiental na escola de ensino fundamental. In: IV EREBio, 2007, Seropédica/RJ. Painel Temático: Desafios da educação ambiental na escola básica. IV Encontro Regional de Ensino de Biologia. Seropédica: SBEnBio/UFRRJ, v. 1. p. 1-11, 2007. LOUREIRO, C. F. B. O que queremos com política de educação ambiental no Brasil? II CONGRESSO NACIONAL DE ALFABETIZAÇÃO E EDUCAÇÃO AMBIENTAL. Rio Grande, RS, p. 1-17, 2008.

LOUREIRO, C. F. B.; COSSIO, M. F. B. Um olhar sobre a educação ambiental nas escolas: considerações iniciais sobre os resultados do projeto. In: MELLO, S.; TRAJBER, R. (Orgs.). Vamos cuidar do Brasil: conceitos e práticas em educação ambiental. Brasília: MEC/UNESCO, v. 1, 2007. p. 57-64.

MESCHKAT, K. Uma crítica a la ideologia de la 'sociedad civil'. In: HENGSTENBERG, P.; KOHUT, K.; MAIHOLD, G. (Eds.) Sociedad civil em América Latina: representación de interesses y governabilidad. Caracas: Nueva Sociedad, 1999. 
SAVIANI, D. Transformações do capitalismo, do mundo do trabalho e da educação. In: LOMBARDI, J. C.; SAVIANI, D. SANFELICE, J. L. (Orgs.). Capitalismo, Trabalho e Educação. Campinas: Autores Associados. HISTEDBR. 2005. p. 13-24.

TONSO, S. Cardápio de aprendizagem. In: FERRARO JÚNIOR, L. A. (Org.) Encontros e Caminhos: formação de educadoras(es) ambientais e coletivos educadores. v. 1. Brasília: MMA: Diretoria de Educação Ambiental, 2005. p. 49-56.

TOZONI-REIS, M. F. C. A inserção da educação ambiental na escola. Boletim TV Escola, v. 01, p. 46-54, 2008.

TRAJBER, R. e MENDONÇA, P. (Orgs.). Educação na diversidade: o que fazem as escolas que dizem que fazem educação ambiental. Brasília: Secretaria de Educação Continuada, Alfabetização e Diversidade, 2006.

TRISTÃO, M.; FASSARELLA, R. C. Contextos de aprendizagem: encontros e eventos. In: FERRARO JÚNIOR, L. A. (Org.) Encontros e Caminhos: formação de educadoras(es) ambientais e coletivos educadores. v. 2. Brasília: MMA: Diretoria de Educação Ambiental, 2007. p. 87-94.

\section{NOTAS}

$1 \mathrm{Na}$ tradução oficial em português, é empregado o termo Consciência Linguística Crítica (CLC).

2 No artigo "A Educação Permanente: um modelo de discurso ideológico importado", publicado na Revista de Cultura Vozes, n. 8, de outubro de 1978, que desenvolve um dos aspectos do seu tema de doutoramento sobre a Educação Permanente.

3 Com a publicação de um relatório sobre educação pelo Ministério da Reconstrução da Inglaterra, no qual se fala de uma educação que devia corresponder às necessidades das pessoas durante toda a vida (p. 92). Como expressão, aparece em 1955, utilizada por Pierre Arents, num projeto de reforma educacional, na França (p. 94).

4 Meschkat (1999, p. 40) afirma que esse conceito se difundiu na América Latina no período das ditaduras militares, sendo "civil" utilizado como sinônimo de não-militar. Nesse contexto de crítica ao autoritarismo dos regimes instaurados, o fortalecimento não foi de uma "sociedade civil popular", mas da "sociedade civil burguesa" (p. 43).

5 O desenvolvimento sustentável e a responsabilidade socioambiental são bons exemplos dessa estratégia.

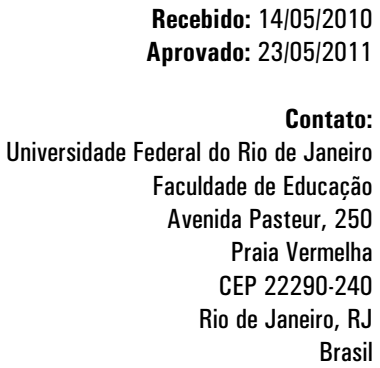

Educação em Revista | Belo Horizonte | v.27 | n.02 | p.177-196 | ago. 2011 